\title{
Estimation Using Differential Evolution for Optimal Crop Plan
}

\author{
Millie Pant ${ }^{1}$, T Radha ${ }^{1}$, Deepti Rani ${ }^{2}$, Ajith Abraham ${ }^{3}$ and D. K. Srivastava ${ }^{4}$ \\ ${ }^{1}$ Department of Paper Technology, IIT Roorkee, India. \\ ${ }^{2}$ University of Evvora, Núcleo da Mitra, 7002-054, Évora 7000 Évora, Portugal \\ ${ }^{3} \mathrm{Q} 2 \mathrm{~S}$, Norwegian University of Science and Technology, Norway. \\ ${ }^{4}$ Department of Hydrology, IIT Roorkee, India. \\ millifpt@iitr.ernet.in, t.radha@ieee.org, deeptinatyan@yahoo.com, ajith.abraham@ieee.org, \\ dkshyfhy@iitr.ernet.in.
}

\begin{abstract}
This paper presents an application of Differential Evolution (DE) to determine optimal crop plan for command area of Pamba-Achankovil-Vaippar (PAV) link project, so as to maximize the net irrigation benefit. The mathematical model of the problem is linear in nature subject to various constraints due to availability of total land area, water, fertilizers, seeds and manure, etc. Numerical results show that DE gives a better performance in comparison to the usual software tools used for solving such problems.
\end{abstract}

Keywords: Differential Evolution, Reservoir, Crop Plan, Optimization.

\section{Introduction}

DE has emerged as one of the most promising contemporary optimization technique in the past few years. Some of the reasons for the popularity of DE include easy implementation, little parameter tuning and fast convergence. It has been successfully applied to solve a wide range of optimization problems such as clustering [1], unsupervised image classification [2], digital filter design [3], optimization of nonlinear functions [4], chemical engineering processes [5] and multi-objective optimization [6] etc. In the present study we discuss the performance of DE to obtain optimal crop plans under adequate, normal and limited irrigation water availability for irrigation area under the PAV link project. A linear programming based optimization model is used for this.

The proposed Pamba-Achankovil-Vaippar Link project has three storage reservoirs, two tunnels, necessary canal system and a few power generating units [7]. The Punnamedu reservoir (reservoir-2) is located at a higher elevation on river Pamba Kal $\mathrm{Ar}$ in the Pamba basin of Karala state, which serves a part/full of its downstream mandatory requirements and supplies surplus water to reservoir-1 by intra-basin export of surplus water (diversion) through tunnel-2. The Achankovil Kal Ar reservoir (reservoir-1) located on Achankovil Kal Ar river in Achankovil river basin of Kerala state, supplies water for irrigation purposes to the state of Tamilnadu, through tunnel-1 to the main canal. The water from main canal is then distributed to the command area of Vaippar basin in Tamilnadu state. The reservoir is proposed as a within-the-year storage scheme. Figure 1 shows a schematic representation of the PAV link diversion system. Besides this, reservoir-1 releases water for power 
generation. The Achankovil reservoir (reservoir-3), which is located on Achankovil river in the Achankovil river basin of Kerala state, besides acting as a pumped storage scheme accommodating the water drawn from the upstream reservoir-1, also serves the purpose of releasing water to downstream to meet its downstream mandatory demands. Also, if there is deficit at reservoir- 1 the surplus water of reservoir- 3 can be pumped back to reservoir-1. The monthly inflow at reservoir- 1 for the 50 percent, 75 percent and 90 percent water year dependable flows are shown in Figure 2.

The GCA (gross command area) potential and CCA (culturable command area) potential of the project would be 145,573 and 101,555 ha, respectively. The proposal is to irrigate 91,400 ha (CCA actually considered) of area per annum with an irrigation intensity of 90 percent. The proposed cropping pattern was formulated by the Tamilnadu State Agriculture Department exclusively for this project. Crop areas given in the report were determined on the basis of the food requirements of the population likely to be benefited from project. The suggested cropping pattern consists of 8 crops namely; Paddy, Oilseed, Jowar, Vegetables (Brinjal, Ladyfinger and Beans), Pulses, Bajra, Cotton and Chillies; the proposed corresponding area allocation for each crop is 15234, 7109, 12187, 15233, 6093, 15233, 12187 and 8124 ha, respectively, and crop yields from these crops under irrigation area; 5.39, 1.51, 2.56, 3.0, 0.741, 2.56, 1.66 and 1.51 metric tones (M.T) per unit cropped area, respectively. The gross irrigation requirement for the command area as per project is $635 \mathrm{mcm}$ including transmission losses.

The total production from proposed irrigation, cost of produce and expenses on cultivation of various crops under irrigation conditions, i.e., total cost on seeds, fertilizers, manure, irrigation charges and labour per unit area of each crop is available from project report [8]. The water release from reservoir-1 for irrigation is obtained through joint operation of the reservoir system with the help of successive approximation dynamic programming model [9]. The water available at the main canal is further distributed among the areas under Reaches-I, II and III. In this study, however, optimal cropping patterns are presented for the total CCA for water available during 50 percent, 75 percent and 90 percent water year dependable flows. The remaining of the paper is organized as follows; in section 2, we briefly describe the working of DE. In section 3, we discuss the mathematical model used in the present study. Section 4 deals with experimental settings. In section 5, we give numerical results and the paper finally concludes with section 6 .

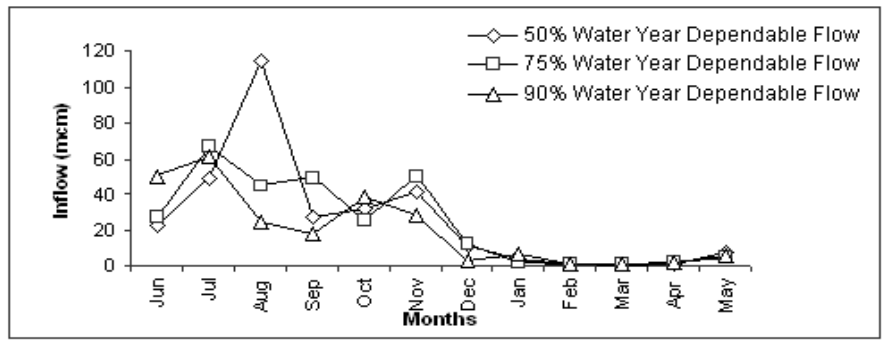

Figure 2 Monthly inflows at Reservoir-I 


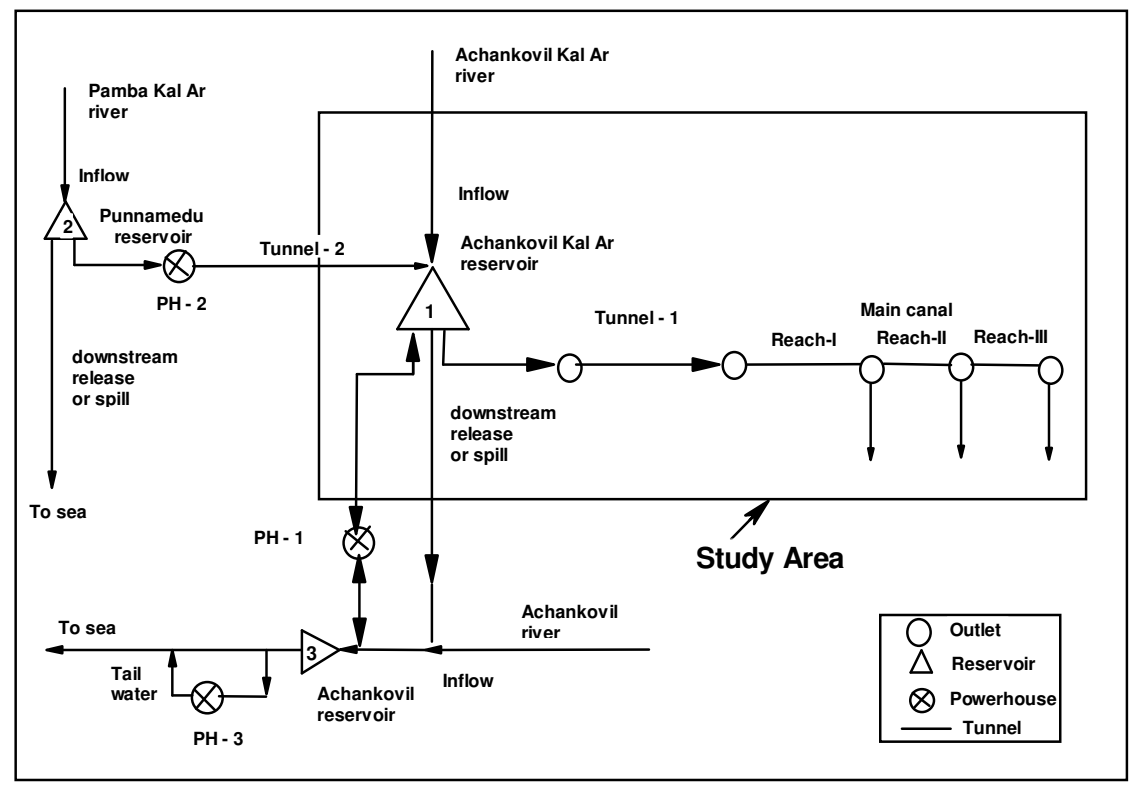

Figure 1 Schematic Diagram for PAV Link Diversion System

\section{Differential Evolution}

Differential Evolution was proposed by Storn and Price [10]. It is a population based algorithm like genetic algorithms using the similar operators; crossover, mutation and selection. The main difference in constructing better solutions is that genetic algorithms rely on crossover while DE relies on mutation operator [11]. DE works as follows: First, all individuals are initialized with uniformly distributed random numbers and evaluated using the fitness function provided. Then the following will be executed until maximum number of generation has been reached.

For a D-dimensional search space, each target vector $x_{i, g}$, a mutant vector is generated by

$$
v_{i, g+1}=x_{r_{1}, g}+F *\left(x_{r_{2}, g}-x_{r_{3}, g}\right)
$$

where $r_{1}, r_{2}, r_{3} \in\{1,2, \ldots ., N P\}$ are randomly chosen integers, must be different from each other and also different from the running index i. F $(>0)$ is a scaling factor which controls the amplification of the differential evolution $\left(x_{r_{2}, g}-x_{r_{3}, g}\right)$. In order to increase the diversity of the perturbed parameter vectors, crossover is introduced [12]. The parent vector is mixed with the mutated vector to produce a trial vector $u_{j i, g+1}$, 


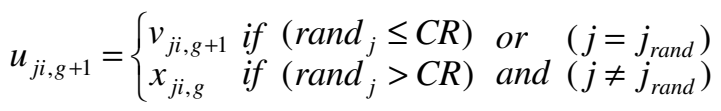

where $\mathrm{j}=1,2, \ldots \ldots . \mathrm{D} ;$ rand $_{j} \in[0,1]$; $\mathrm{CR}$ is the crossover constant takes values in the range $[0,1]$ and $j_{\text {rand }} \in(1,2, \ldots . ., D)$ is the randomly chosen index.

Selection is the step to choose the vector between the target vector and the trial vector with the aim of creating an individual for the next generation.

\section{Mathematical Model}

A linear programming based optimization model is used for crop planning. The model maximizes net returns from crops and yields optimal crop plan and monthly releases required from reservoir-1. Surface water, land availability, fertilizers (N, P, and K), seeds and manure requirements are considered as constraints in the model. For the purpose of modeling, the crops have been segregated as food grains, cash crops and others. Paddy, Jowar and Bajra are clubbed together as these falls under the category of food grains.

\section{Crop Planning Model}

Objective function:

$$
\begin{aligned}
& \operatorname{Max} \mathrm{Z}=\mathrm{G}_{\mathrm{T}}-\mathrm{P}_{\mathrm{T}} \\
& \mathrm{G}_{\mathrm{T}}=\sum_{\mathrm{i}=1}^{\mathrm{N}} \mathrm{y}_{\mathrm{i}} \mathrm{b}_{\mathrm{i}} \mathrm{A}_{\mathrm{i}} \text { and } \mathrm{P}_{\mathrm{T}}=\sum_{\mathrm{i}=1}^{\mathrm{N}}\left(\mathrm{CS}_{\mathrm{i}}+\mathrm{CM}_{\mathrm{i}}+\mathrm{CF}_{\mathrm{i}}+\mathrm{CI}_{\mathrm{i}}+\mathrm{CLH}_{\mathrm{i}}\right) \mathrm{A}_{\mathrm{i}}
\end{aligned}
$$

In the above equation $\mathrm{Z}=$ annual net return from irrigated agriculture, $\mathrm{G}_{\mathrm{T}}=$ total annual gross returns from crops, $\mathrm{P}_{\mathrm{T}}=$ total annual net expenses on cultivating crops, $\mathrm{N}=$ total number of crops, $\mathrm{i}=1,2, \ldots, 8$ for Paddy, Oilseeds, Jowar, Vegetables, Pulses, Bajra, Cotton and Chillies, respectively, $\mathrm{A}_{\mathrm{i}}=$ area under ith crop, $\mathrm{CS}_{\mathrm{i}}=$ expenses on seeds for ith crop per unit area, $\mathrm{CM}_{\mathrm{i}}=$ expenses on manure for ith crop per unit area, $\mathrm{CF}_{\mathrm{i}}=$ expenses on fertilizers for ith crop per unit area, $\mathrm{CLH}_{\mathrm{i}}=$ expenses on labor and machinery for ith crop per unit area, $\mathrm{CI}_{\mathrm{i}}=$ expenses on irrigation water charges for ith crop per unit area, $\mathrm{y}_{\mathrm{i}}=$ crop yield in weight units from ith crop per unit area, and $b_{i}=$ value of crop produce from ith crop per unit yield.

\section{Constraints}

(i) Surface Water Availability Constraint

The volumes of water releases should be less than or equal to the surface water available, i.e.,

$$
\sum_{i=1}^{N}\left(W_{i, t}\right) A_{i} \leq R_{t} \quad \text { for all } t
$$


where $\mathrm{W}_{\mathrm{i}, \mathrm{t}}=$ gross irrigation requirement of ith crop during time period $\mathrm{t}$ in terms of depth , $\mathrm{A}_{\mathrm{i}}=$ area under ith crop and $\mathrm{R}_{\mathrm{t}}=$ irrigation water released from reservoir in time period $\mathrm{t}$.

\section{(ii) Land Availability Constraints:}

The net area allocated to the given crops should be less than or equal to the total area available, i.e.,

$$
\sum_{i=1}^{N}\left(\lambda_{i, t}\right) A_{i} \leq A_{T}, \quad \text { for all } t \text { and } \sum_{i=1}^{N} A_{i} \leq A_{T}
$$

where $\lambda_{\mathrm{i}, \mathrm{t}}=$ land use coefficient of the ith crop during time period $\mathrm{t}$ and $\mathrm{A}_{\mathrm{T}}=$ total area under irrigation per annum.

\section{(iii) Yield Requirement Constraint:}

Yield produced from the crops should be greater than or equal to the proposed yield requirement, i.e.,

$$
\sum_{\mathrm{i}} \mathrm{y}_{\mathrm{i}} \mathrm{A}_{\mathrm{i}} \geq \sum_{\mathrm{i}} \mathrm{y}_{\mathrm{T}}^{\mathrm{i}} \quad \text { fori }=1,3 \text { and } 6 \quad \text { and } \mathrm{y}_{\mathrm{i}} \mathrm{A}_{\mathrm{i}} \geq \mathrm{y}_{\mathrm{T}}^{\mathrm{i}} \quad \text { foralli }
$$

where $\mathrm{y}_{\mathrm{T}}^{\mathrm{i}}=$ total yield required from $\mathrm{i}^{\text {th }}$ crop.

(iv) Fertilizers Availability Constraints:

Quantity of fertilizer of type $f$ required will be less than or equal to the quantity of fertilizer type $f$ available, i.e.,

$$
\sum_{\mathrm{i}=1}^{\mathrm{N}} \mathrm{F}_{f, \mathrm{i}} \mathrm{A}_{\mathrm{i}} \leq \mathrm{F}_{f, \mathrm{~T}} \quad \text { forall } f
$$

where $\mathrm{F}_{f, \mathrm{i}}=$ quantity of fertilizer type $f$ required per unit area for ith crop and $\mathrm{F}_{f, \mathrm{~T}}=$ total available quantity of fertilizer of type $f$. Three types of fertilizers have been considered in the application of model, i.e., Nitrogen, Phosphorus and Potassium (N, $\mathrm{P}, \mathrm{K})$.

(v) Manure Availability Constraint:

Total quantity of manure required will be less than or equal to the total quantity of manure available, i.e.,

$$
\sum_{i=1}^{N} M_{i} A_{i} \leq M_{T}
$$

where $\mathrm{M}_{\mathrm{i}}=$ quantity of manure required per unit area for ith crop and $\mathrm{M}_{\mathrm{T}}=$ total available quantity of manure.

\section{(vi) Seeds Availability Constraint:}

$\mathrm{S}_{\mathrm{i}} \mathrm{A}_{\mathrm{i}} \leq \mathrm{S}_{\mathrm{T}} \quad$ for all $\mathrm{i}$ 
where $S_{i}=$ quantity of seeds required per unit area for ith crop and $S_{i, T}=$ total available quantity of seeds for ith crop.

\section{(vii) Bounds on Areas under Various Crops:}

$\mathrm{A}_{\mathrm{i}, \min } \leq \mathrm{A}_{\mathrm{i}} \leq \mathrm{A}_{\mathrm{i}, \max }$

where $A_{i, \min }=$ lower limit on the area under ith crop and $A_{i, \max }=$ upper limit on the area under ith crop.

A minimum crop area constraint has been specified on each crop so as to see that area occupied by crops does not fall below area under rain-fed cultivation. It has also been specified that area proposed under cotton and chillies should not be more than 18 percent and 17 percent of annual irrigation. This condition is justified because their yields have high revenues and optimally higher area allocation to these crops may cause reduction in food grain output, which is socially undesirable. It has been considered essential that total food grain production should not be less than 101, 995 M.T.

\section{Experimental Settings}

In this section we give the data used for the mathematical model used in section 3 and the parameter settings for DE. From information available [13] estimates of average values of quantities/ha required for each crop for resource inputs, i.e., seeds, manure and fertilizers are obtained. Total requirements of these resources are obtained from these values and crop area allocation as per project report. Initially it was assumed that total quantity available for each resource is equal to total quantity required for the resource. The crop planning model is solved using LINGO package. The first trial run is made of the model assuming that the amount of each resource available is equal to the required amount, and from results it was seen that out of the total CCA, i.e., 91400 ha only 88818.64 ha is allocated to the crops, i.e., with this trial the total CCA was not allocated to various crops (Table 1). Further model runs were made by varying quantity of resource availability in some percent of required amount the area allocations for these trials are given inTable 1 .

Finally it was assumed that 120 percent of the total quantity initially estimated for each resource may be considered as the extent of quantity available as input, for which almost all the area proposed has been allocated (Table 2).

\section{Parameter settings for DE:}

As discussed in the earlier section, DE requires very few parameter settings in comparison to other Evolutionary algorithms. Only three parameters; Population size, crossover constant and scaling parameter are needed for DE.

Population size: 30 ; crossover constant $\mathrm{CR}=0.5$; Scaling parameter $\mathrm{F}=0.5$.

Maximum number of generation: 1000; Number of runs: 30; 


\begin{tabular}{|c|c|c|c|c|}
\hline \multirow{2}{*}{\multicolumn{2}{|c|}{$\begin{array}{l}\text { Table 1. Optimal area } \\
\text { allocations with variable } \\
\text { resource inputs available }\end{array}$}} & \multicolumn{3}{|c|}{ Table 2. Extents of resource available } \\
\hline & & \multirow{2}{*}{\multicolumn{2}{|c|}{ Resource }} & Extent \\
\hline \multirow{3}{*}{$\begin{array}{l}\text { Resource } \\
\text { Inputs }\end{array}$} & \multirow{3}{*}{$\begin{array}{l}\text { Optimal Area } \\
\text { Allocations } \\
\text { (ha) }\end{array}$} & & & Availability $^{+}$ \\
\hline & & \multirow{3}{*}{$\begin{array}{l}\text { Fertilizers } \\
\quad(\mathrm{kg})\end{array}$} & $\mathrm{N}$ & 5774510 \\
\hline & & & $\mathrm{P}$ & 4911240 \\
\hline $80 \%$ & 73120.00 & & $\mathrm{~K}$ & 2303256 \\
\hline $90 \%$ & 74384.31 & \multicolumn{2}{|c|}{ Manure (M.T.) } & 1431135 \\
\hline \multirow{2}{*}{$100 \%$} & \multirow{2}{*}{88818.64} & \multirow{8}{*}{$\begin{array}{l}\text { Seeds } \\
(\mathrm{kg})\end{array}$} & Paddy & 1188252 \\
\hline & & & Oil seeds & 2102154 \\
\hline $110 \%$ & 89754.08 & & Jowar & 93838.8 \\
\hline $120 \%$ & 91399.99 & & Vegetables & 178403.04 \\
\hline \multirow{4}{*}{$130 \%$} & \multirow{4}{*}{91400.00} & & Pulses & 329049 \\
\hline & & & Bajra & 255906 \\
\hline & & & Cotton & 319893 \\
\hline & & & Chillies & 329049 \\
\hline
\end{tabular}

\section{Numerical Results}

The performance of DE is compared with LINGO, which is another popular software tool for solving Linear Programming Problems. From the numerical results given in Table 3, it can be seen that for 50\% water year dependable flow, both DE and LINGO gave exact results. However for $75 \%$ and $90 \%$ water year dependable flow performance of DE is superior to LINGO in terms of net profit. For $75 \%$ water year dependable flow, the net profit as obtained by DE is 16503.3 and by LINGO is 16449.01, which shows an improvement of $0.33 \%$. For $90 \%$ water year dependable flow DE gave a profit of Rs 15319.1, whereas profit obtained by LINGO is Rs 15264.7 , which shows an improvement of $0.36 \%$. Also we get to know the optimal area allocation for different crops while using DE and LINGO. The time taken by DE and LINGO are same for all the three cases.

\section{Conclusion}

In the present study an application of DE is shown for determining the optimal cropping pattern so as to maximize the net profit under the given conditions. Its performance is compared vis-à-vis LINGO, which is a very popular tool for solving Linear Programming Problems. Numerical results show that DE gives a superior performance in comparison to LINGO for $75 \%$ and $90 \%$ water year dependable flow. Thus DE may be considered as an alternative for solving such type of problems. In future we shall be comparing the performance of DE with other techniques like PSO for solving similar types of problems. 
. Table 3. Performance Comparison of DE with LINGO for $50 \%, 75 \%$ and $90 \%$ water year dependable flow

\begin{tabular}{|l|l|l|l|l|l|l|}
\hline & \multicolumn{2}{|l|}{\begin{tabular}{l}
\multicolumn{2}{l|}{$\begin{array}{l}\text { l0\% water year } \\
\text { dependable flow }\end{array}$} \\
dependable flow
\end{tabular}} & \multicolumn{2}{l|}{$\begin{array}{l}\text { 90\% water year } \\
\text { dependable flow }\end{array}$} \\
\hline ITEM & DE & LINGO & DE & LINGO & DE & LINGO \\
\hline A1 & 2818.71 & 2818.639 & 0.00161 & 0 & 0.00019 & 0 \\
\hline A2 & 15233 & 15233 & 15233 & 15233 & 13125.4 & 13125.35 \\
\hline A3 & 7109 & 7109 & 5034.2 & 5033.97 & 0.00044 & 0 \\
\hline A4 & 8124 & 8124 & 8124 & 8124 & 8124 & 8124 \\
\hline A5 & 12186 & 12186.99 & 12186 & 12186.99 & 0.00023 & 0 \\
\hline A6 & 4433.27 & 4433.273 & 5193.36 & 5193.36 & 927.386 & 927.3857 \\
\hline A7 & 15233 & 15233 & 16000 & 15876.04 & 16000 & 15876.04 \\
\hline A8 & 14273.1 & 14273.09 & 14624.4 & 14592.21 & 14624.4 & 14592.21 \\
\hline $\begin{array}{l}\text { Objective } \\
\text { value }\end{array}$ & $\mathbf{1 6 5 1 3 . 1}$ & $\mathbf{1 6 5 1 3 . 1}$ & $\mathbf{1 6 5 0 3 . 3}$ & 16449.01 & $\mathbf{1 5 3 1 9 . 1}$ & 15264.74 \\
\hline
\end{tabular}

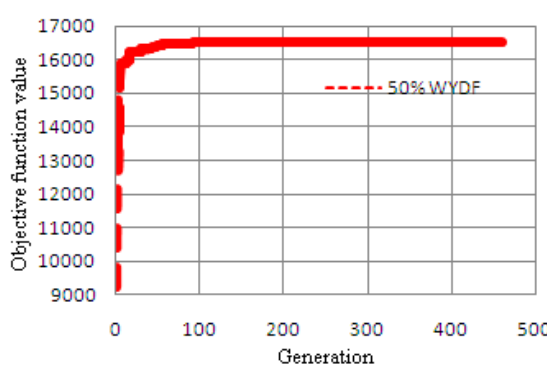

Fig. 1(a)

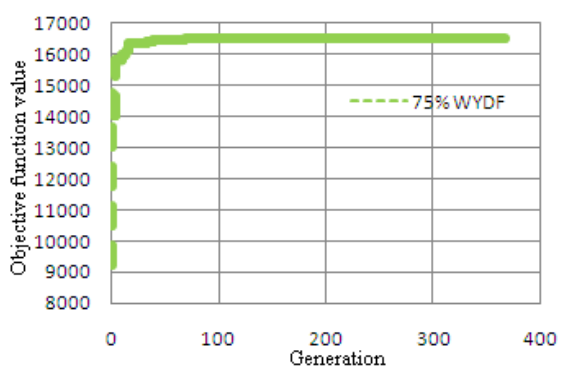

Fig. 1(b)

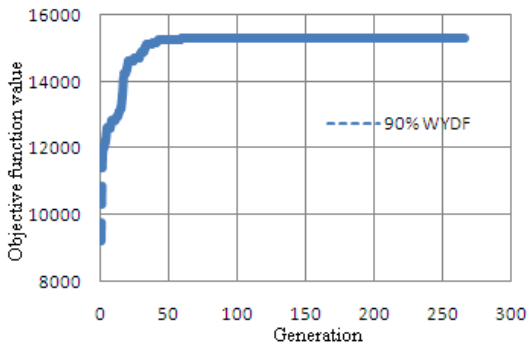

Fig. 1(c)

Figures 1(a), 1(b), 1(c) represent convergence graphs for $50 \%, 75 \%$ and $90 \%$ water year dependable flow 


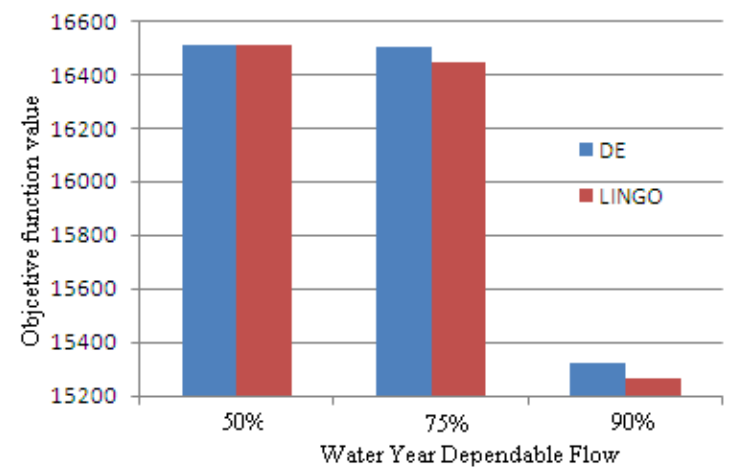

Fig.2 Objective function value obtained by DE and LINGO

\section{References}

1. S.Paterlini, T.Krink, "High performance clustering with differential evolution." In: Proceedings of the IEEE Congress on Evolutionary Computation, vol. 2, 2004.pp. 20042011.

2. M.Omran, A.Engelbrecht, A.Salman, Differential evolution methods for unsupervised image classification.” In: Proceedings of the IEEE Congress on Evolutionary Computation, vol. 2, 2005a. pp. 966-973.

3. R.Storn,'Differential evolution design for an IIR-filter with requirements for magnitude and group delay". Technical Report TR-95-026, International Computer Science Institute, Berkeley, CA 1995

4. B.Babu, R.Angira, "Optimization of non-linear functions using evolutionary computation". In: Proceedings of the $12^{\text {th }}$ ISME International Conference on Mechanical Engineering, India, 2001 pp. 153-157.

5. R.Angira, B.Babu, "Evolutionary computation for global optimization of non-linear chemical engineering processes." In: Proceedings of International Symposium on Process Systems Engineering and Control, Mumbai, 2003.pp. 87-91.

6. H. Abbass, "A memetic pareto evolutionary approach to artificial neural networks" Lecture Notes in Artificial Intelligence, vol. 2256. Springer, 2002a pp. 1-12.

7. Ramakrishnan, M., Systems Analysis of Multireservoirs, M.E. Dissertation, Dept. of Hydrology, Univ. of Roorkee, Roorkee, India, 1999.

8. Feasibility Report of Pamba-Achankovil-Vaippar Link Project, NWDA, Ministry of Water Resources, New Delhi, India, 1995.

9. Deepti Rani, Multilevel Optimization of a Water Resources System, Ph.D. Thesis, Dept. of Mathematics, Indian Inst. of Tech., Roorkee, India, 2004.

10. R. Storn and K. Price, "Differential Evolution - a simple and efficient adaptive scheme for global optimization over continuous spaces", Technical Report, International Computer Science Institute, Berkley, 1995.

11. D. Karaboga and S. Okdem, "A simple and Global Optimization Algorithm for Engineering Problems: Differential Evolution Algorithm”, Turk J. Elec. Engin. 12(1), 2004, pp. 53 - 60.

12. R. Storn and K. Price, "Differential Evolution - a simple and efficient Heuristic for global optimization over continuous spaces", Journal Global Optimization. 11, 1997, pp. 341 359.

13. Handbook on Agriculture, ICAR, Ministry of Agriculture, New Delhi, India, 1997. 